\title{
Produção primária e características fotossintéticas do fitoplâncton na regiáo sueste do Brasil
}

\author{
Frederico Pereira BRANDINI
}

Universidade Federal do Paraná

Centro de Biologia Marinha

(Av. Beira Mar s/n, Pontal do Sul 83200, Paranaguá, PR)

- Abstract: Primary production of phytoplankton (C-14) was obtained at coastal, mid-shelf and oceanic stations off the Southeastern Brazil, with the in situ simulated method. Productivity rates in the euphotic zone were calculated at two stations using chlorophyll and light data and the results were $35 \%$ lower than those obtained by the simulated in situ method. Primary production rates varied from 0.04-0.49 $\mathrm{gC} / \mathrm{m}^{2} / \mathrm{d}$ in winter 1982 , and from $0.1-0.32 \mathrm{gC} / \mathrm{m}^{2} / \mathrm{d}$ in autumn 1983. In addition, photosynthetic characteristics of the phytoplankton were studied. The P x I curves and the vertical distribution of assimilation number indicated a better photoadaptation of the sub-surface phytoplankton in relation to the surface populations.

- Descriptors: Phytoplankton, Primary production, Photosynthesis, Southeastern Brazil.

- Descritores: Fitoplâncton, Produção primária, Fotossíntese, Regiāo suesteBrasil.

\section{Introdução}

Apesar da complexidade estrutural da teia alimentar dos ecossistemas marinhos, é possível avaliar a produção de peixes no mar com base nas medidas de produção primária (Ryther,1969) ou, pelo menos, prever diferenças anuais dos estoques comerciais associados aos ciclos de produção de acordo com a regiāo (Cushing, 1975). Estudos realizados na Corrente da Califórnia, identificaram as relaçōes entre o tamanho da população de larvas de anchova e o ciclo de produção primária do fitoplâncton (Smith \& Eppley, 1982).

A região sueste do Brasil contribui com uma fração significativa da produçāo pesqueira nacional (Paiva, 1986; Matsuura, 1986a), predominanemente sardinha, atum e bonito, cujos ciclos de vida estão evidentemente associados à produção fitoplanctônica. As flutuações anuais no recrutamento dessas espécies podem ser explicadas por fenômenos oceanográficos cíclicos (termoclina sazonal) ou nảo previsíveis (ressurgências) que alteram a estabilidade da coluna de água e a estrutura taxonômica do fitoplâncton, a exemplo do que foi observado por Lasker (1978) ao estudar o ciclo de vida da anchova da Califórnia (Engraulis mordax).

As ressurgências da Água Central do Atlântico Sul ao longo do talude continental da regiāo sueste do Brasil (Mesquita et al., 1983; Brandini, 1990) deslocam a termoclina sazonal em direção à superfície e transformam provisoriamente o sistema de "produção regenerativa" em "produçāo nova" (sensu Dugdale \& Goering, 1967), alterando totalmente a densidade e a composição específica do fitoplâncton em áreas afastadas da costa (Brandini et al., 1989). Esses fenômenos devem afetar, por exemplo, os ciclos de vida do "bonito" (Katsuwonus pelamis) cujos estoques concentram-se ao longo do talude continental (Jablonski \& Matsuura, 1985) sendo indiretamente favorecidos pelas ressurgências na borda da plataforma.

Com exceção dos trabalhos de Aidar-Aragão et al. (1980) e Vieira \& Teixeira (1981), que apresentam valores de fotossíntese e excreção do fitoplâncton na superfície, as estimativas da taxa de produção primária na zona eufótica sobre a plataforma intermediária e áreas oceânicas adjacentes da região sueste foram iniciadas recentemente durante as expediçōes oceanográficas da Diretoria de Hidrografia e Navegaçāo do Ministério da Marinha (Operaçāo Sueste - DHN, 1985, 1986a,b). Uma ampla malha de estaçōes foi amostrada em regime sazonal com o objetivo de estudar as características fotossintéticas do fitoplâncton e suas relaçōes com a estrutura oceanográfica do ambiente pelágico. Os parâmetros ambientais e a produtividade potencial das diferentes massas de água foram estudados em vários períodos sazonais (Brandini, 1988a, 1990), e a 
distribuição espacial do fitoplâncton em relação ao regime hidrográfico ja foi discutida em alguns desses períodos (Brandini, 1988b; Brandini \& Moraes, 1986).

O presente trabalho contém dados preliminares de produção primária na coluna eufótica e características fotossintéticas do fitoplâncton obtidos durante o inverno de 1982 e outono de 1983.

\section{Material e métodos}

O N/Oc."Almirante Saldanha" (DHN/MM) percorreu uma malha formada por 91 estaçōes oceanográficas entre 16 de julho e 21 de agosto de 1982 (Operação Sueste I), e entre 3 e 31 de maio de 1983 (Operação Sueste II). As estaçōes indicadas na Figura 1 foram selecionadas para experimentos de fotossíntese e medidas de produção primária do fitoplâncton em áreas costeiras e oceânicas (Fig.1) utilizando-se a técnica do C-14 (Steemann-Nielsen, 1952). A Tabela 1 apresenta os dados de posicionamento, profundidade e data em cada estação.

As medidas de produçāo primária na zona eufótica foram obtidas pelo método "in situ" simulado (Jitts, 1963; Volleinweider, 1969) de acordo com o seguinte procedimento:

As amostras de água foram obtidas com garrafa de Van Dorn em cinco níveis de profundidade equivalentes a 100 (superfície), 60, 30, 16 e $1 \%$ da luz incidente na superfície, com base no coeficiente de extinçảo da luz (k), de acordo com Strickland (1958); sub-amostras foram inoculadas com $\mathrm{NaH}_{2}{ }^{14} \mathrm{CO}_{3}(30 \mu \mathrm{Ci} / 1000 \mathrm{ml})$, colocadas em dois frascos claros e um escuro de $300 \mathrm{ml}$ (regiāo oceânica) ou $125 \mathrm{ml}$ (regiảo costeira) e incubadas com luz natural durante cinco horas. Foram utilizados filtros neutros constituídos por telas de aço inoxidável com aberturas de malha adequadas para cada porcentagem de luz, simulando as condições luminosas originais de cada amostra. A temperatura de incubação foi mantida constante por meio de um fluxo contínuo de água de superfície através do incubador. Após o período de incubação, as amostras foram filtradas em filtros Millipore AA $(0.8 \mu \mathrm{m})$ e a atividade dos filtros foi determinada posteriormente pela técnica da cintilação líquida (Volleinweider, 1969). As taxas de fotossíntese foram calculadas com as equaçōes de Strickland \& Parsons (1972) e a produção na zona eufotica durante o período de incubação foi multiplicada pela razão entre a RST (radiação solar total) diária e a RST do mesmo período para se estimar a taxa de produção diária. Os valores obtidos foram cerca de sete vezes as taxas de produção por hora indicadas na Tabela 4. Portanto, nas estaçōes 1,12 e 58, onde não foi possível a obtenção de curvas diárias de RTS por motivos técnicos, a taxa de produção por hora também foi multiplicada por sete para se obter uma estimativa melhor das taxas diárias. $\mathrm{O}$ mesmo procedimento foi adotado nos experimentos da comissão de outono (maio/1983).

Nas estaçōes 62 e 66 foi utilizado o método da clorofila (Ryther \& Yentsch, 1957), simultaneamente ao método "in situ" simulado, que exige as seguintes informaçōes e condiçōes:

- variação diária da radiação solar na superfície
- relação fotossíntese $x$ luz de uma amostra superficial - distribuição vertical homogênea da clorofila-a na zona eufótica

- coeficiente de extinção da luz, $\mathbf{k}$

A radiação solar total (RST) incidente na superfície foi obtida com um radiômetro KAHLSICO-268 WA310, com leituras a cada 30 minutos entre o nascer e o por do sol. As curvas de fotossíntese $\mathrm{x}$ luz foram determinadas com o mesmo incubador de luz natural utilizado para as incubaçōes com o método "in situ" simulado. A concentraçāo de clorofila- $a$ das amostras foi medida pelo método tricromático (Strickland \& Parsons, 1972) após a extração dos pigmentos com acetona $90 \%$, utilizando-se um espectrofotômetro Micronal B280 e as equaçōes do SCOR-UNESCO (1966). O coeficiente de extinção da luz (k) foi obtido com o disco de Secchi de acordo com Poole \& Atkins (1929).

Com essas informações, determina-se primeiro a variação diária da radiação solar nos níveis selecionados ao longo da zona eufótica através da equação:

$$
\text { Id }=\text { Io. } e^{(-k d)} \quad \text { (Strickland, 1958) }
$$

onde: $I d$ = radiação solar na profundidade $\mathrm{d}$

Io $=$ radiação solar na superfície

$\mathbf{k}=$ coeficiente de extinçāo da luz

Em seguida, cakcula-se a taxa de fotossintese por unidade de clorofila- $a$ em qualquer instante, nos niveis selecionados, a partir dos dados de radiação solar, através da equação:

$$
\begin{array}{r}
\text { F }=\underset{1+(I / I k)}{\text { Fmax } \text { I/lk }} \quad \text { (Parsons \& Takahashi, 1973) } \\
\text { (eq. 2) }
\end{array}
$$

onde:

$\mathbf{F}=$ número de assimilaçāo (fotossíntese/clorofila- $a$ )

Fmax = taxa máxima de fotossíntese em luz saturante $\mathrm{I}=$ intensidade de radiação

Ik = índice de foto-adaptação (Talling, 1957)

Para se obter a taxa de produção primária na zona eufótica por esse método, o valor de F (número de assimilação) foi integrado graficamente ao longo do eixo tempo, obtendo-se as taxas de produçāo em $\mathrm{mgC} / \mathrm{mgClor}-a /$ dia em cada nível de luz. Esses valores foram multiplicados pela concentração de clorofila- $a$ transformando-os em $\mathrm{mgC} / \mathrm{m}^{3} / \mathrm{dia}$. Finalmente, a produtividade diária foi integrada ao longo da zona eufotica e o valor final expresso $\mathrm{em} \mathrm{gC} / \mathrm{m}^{2} / \mathrm{dia}$.

Durante a comissāo de inverno (julho/agosto de 1982) foram obtidas curvas de fotossíntese $x$ luz nas estaçōes 17 , 38, 62 e 66 utilizando-se as porcentagens de luz disponíveis no incubador de luz natural $(100,60,30,16 \mathrm{e}$ $1 \%)$. Na comissāo de outono, além da curva de fotossíntese $\mathrm{x}$ luz obtida na superfície da estaçāo 79 , amostras de superfície das estaçōes $64,68,72$ e 83 foram fracionadas com redes de náilon de $20 \mu \mathrm{m}$ após a incubação, para se determinar as contribuiçōes relativas do nano-e do microplâncton no valor total da produção. 


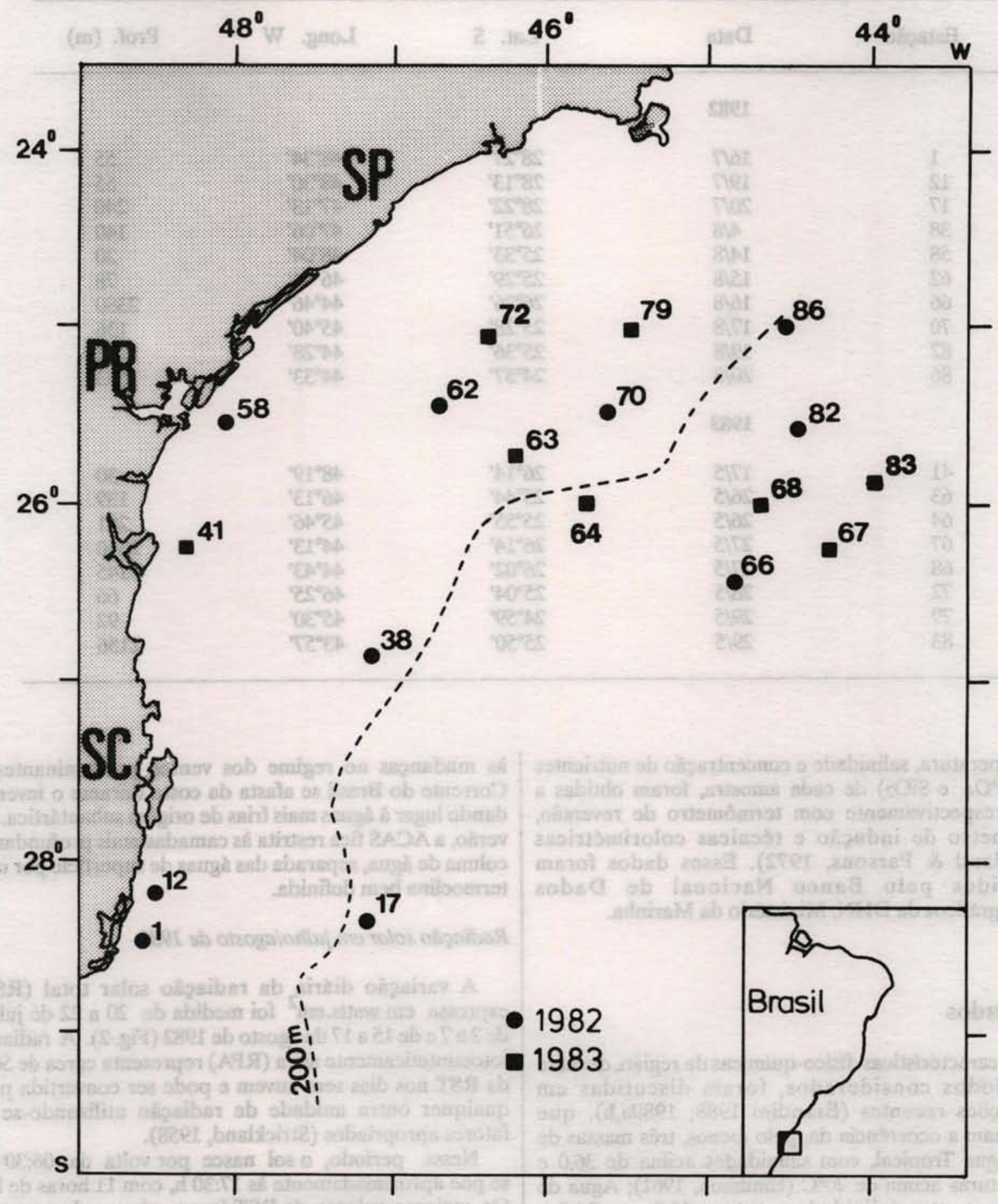

Fig. 1. Mapa da regiẩo estudada e posição das estações de produção primária. 
Tabela 1. Identificação das estações de coleta

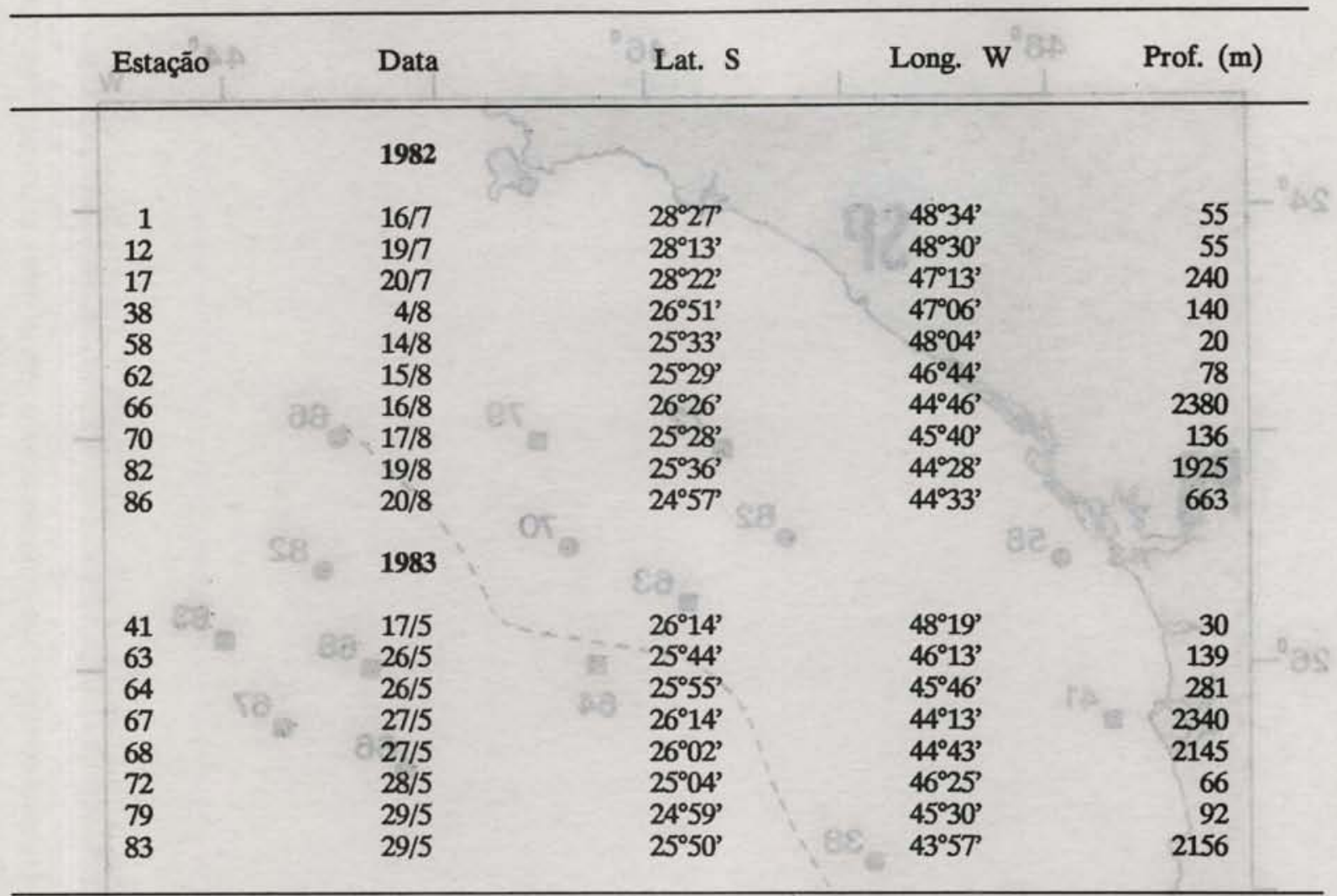

Temperatura, salinidade e concentração de nutrientes $\left(\mathrm{NO}_{3}, \mathrm{PO}_{4}\right.$ e $\left.\mathrm{SiO}_{2}\right)$ de cada amostra, foram obtidas a bordo respectivamente com termômetro de reversão, salinômetro de indução e técnicas colorimétricas (Strickland \& Parsons, 1972). Esses dados foram fornecidos pelo Banco Nacional de Dados Oceanográficos da DHN, Ministério da Marinha.

\section{Resultados}

As características físico-químicas da regiāo, durante os períodos considerados, foram discutidas em publicaçōes recentes (Brandini 1988; 1989a,b), que mencionam a ocorrência de, pelo menos, três massas de água: Água Tropical, com salinidades acima de 36,0 e temperaturas acima de $20^{\circ} \mathrm{C}$ (Emilsson, 1961); Água de Plataforma, com salinidades entre 35,0 e 36,0 e temperaturas acima de $20^{\circ} \mathrm{C}$ (Emilsson, op. cit.); e Água Central do Atlântico Sul - ACAS, localizada em camadas sub-superficiais com salinidades entre 35,0 e 36,0 e temperaturas entre 10 e $20^{\circ} \mathrm{C}$ (Sverdrup et al., 1942). As características dinâmicas dessas massas de água foram originalmente descritas por Emilsson (op. cit.) e recentemente descritas por Miranda (1982), e Matsuura (1986b). Na maior parte do ano a Água Tropical, representada pela Corrente do Brasil, domina as áreas oceânicas e parte da plataforma continental. Entretanto, devido à proximidade com a Convergência Subtropical e às mudanças no regime dos ventos predominantes, a Corrente do Brasil se afasta da costa durante o inverno, dando lugar à águas mais frias de origem subantártica. No verão, a ACAS fica restrita às camadas mais profundas da coluna de água, separada das águas de superfície por uma termoclina bem definida.

\section{Radiação solar em julho/agosto de 1982}

A variação diária da radiação solar total (RST) expressa em watts. $\mathrm{cm}^{2}$ foi medida de 20 a 22 de julho; de 2 a 7 e de 15 a 17 de agosto de 1982 (Fig. 2). A radiação fotossinteticamente ativa (RFA) representa cerca de $50 \%$ da RST nos dias sem nuvem e pode ser convertida para qualquer outra unidade de radiação utilizando-se os fatores apropriados (Strickland, 1958).

Nesse período, o sol nasce por volta das $06: 30 \mathrm{~h} \mathrm{e}$ se pōe aproximadamente às $17: 30 \mathrm{~h}$, com 11 horas de luz. Os maiores valores de RST foram observados entre 10 e 14:00 h e o máximo de 65 watts.cm ${ }^{2}$ foi observado às 11:30 h do dia 4 de agosto. O céu esteve parcialmente encoberto nos dias 22 de julho e 5,6 e 17 de agosto, e totalmente encoberto nos dias 2 de julho e 7 de agosto. Os dias 20 e 21 de julho, e 3, 4, 15 e 16 de agosto apresentaram um padrāo de variaçāo diária muito próximo da curva de Gauss, característica dos dias sem nuvens. A parte hachuriada de alguns gráficos representa períodos do dia em que a RST foi saturante para as reaçōes fotossintéticas na superfície, de acordo com as curvas FxL da Figura 5. 

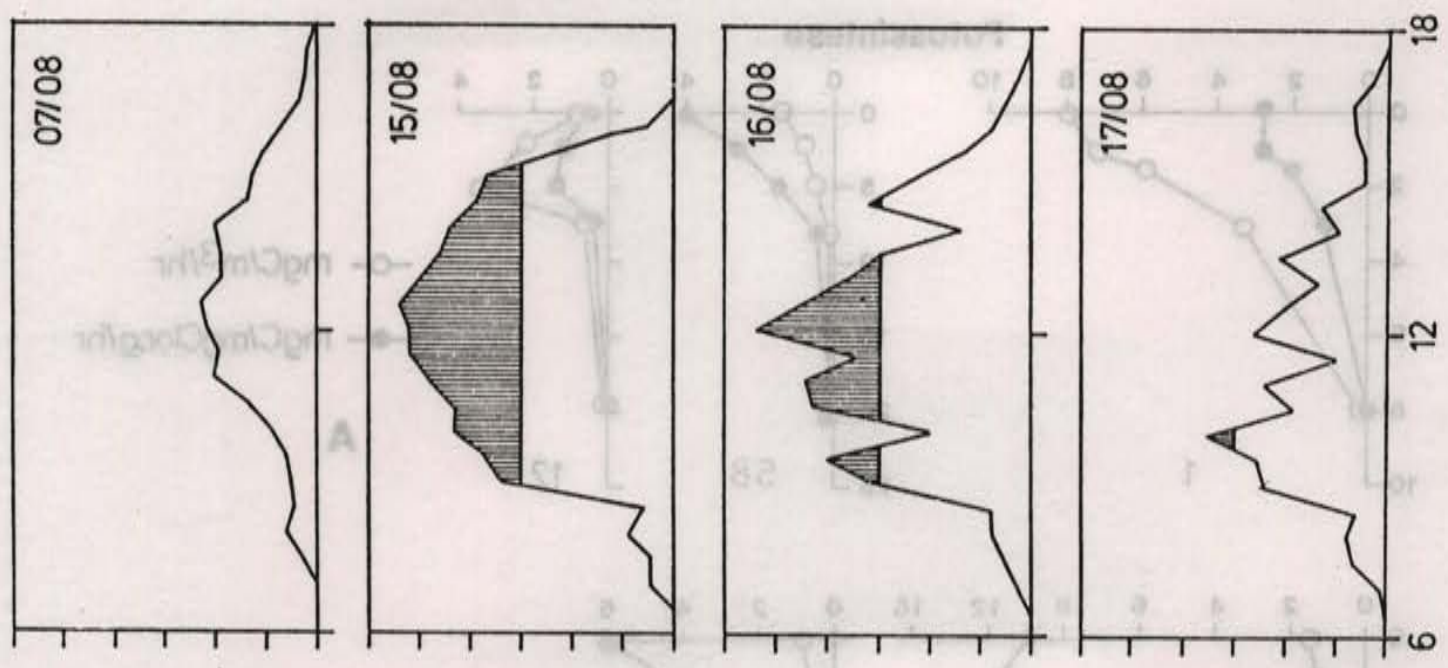

옹
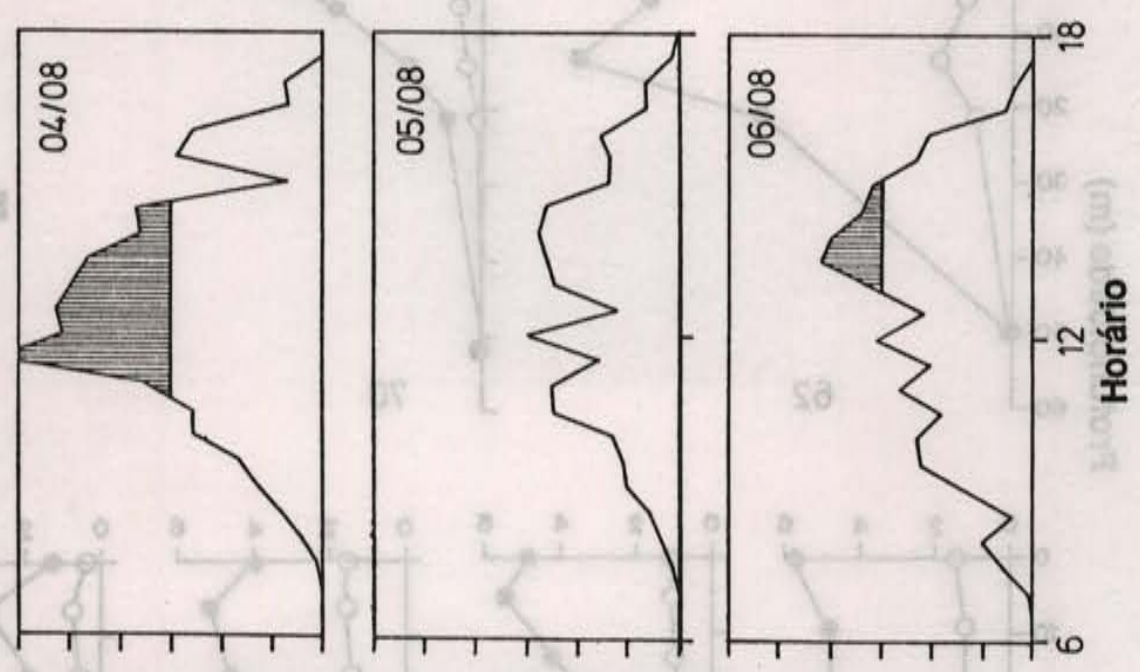

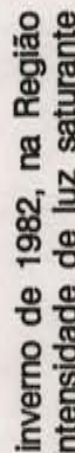
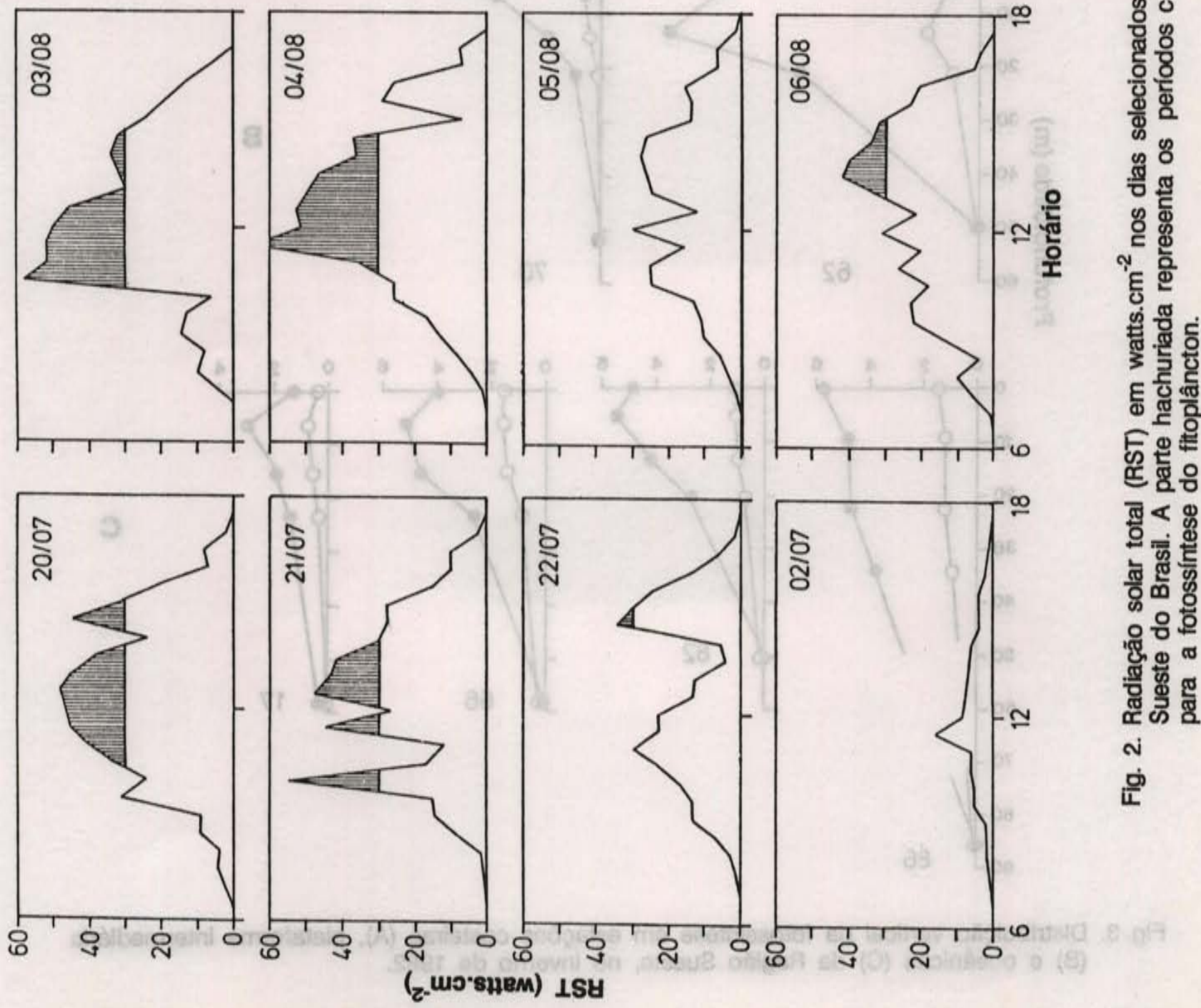


\section{Distribuiçdo vertical da fotossintese}

A Figura 3 indica a distribuição vertical da taxa de fotossintese na zona eufótica de áreas costeiras, intermediárias e oceânicas, em julho/agosto de 1982.
A taxa de fotossíntese por unidade de volume de água variou de 0,01 a $8,09 \mathrm{mgC} / \mathrm{m}^{3} / \mathrm{h}$. Os valores máximos foram obtidos na camada superficial das estaçōes costeiras, decrescendo gradualmente em direçăo à base da zona eufótica. Nas áreas intermediárias da

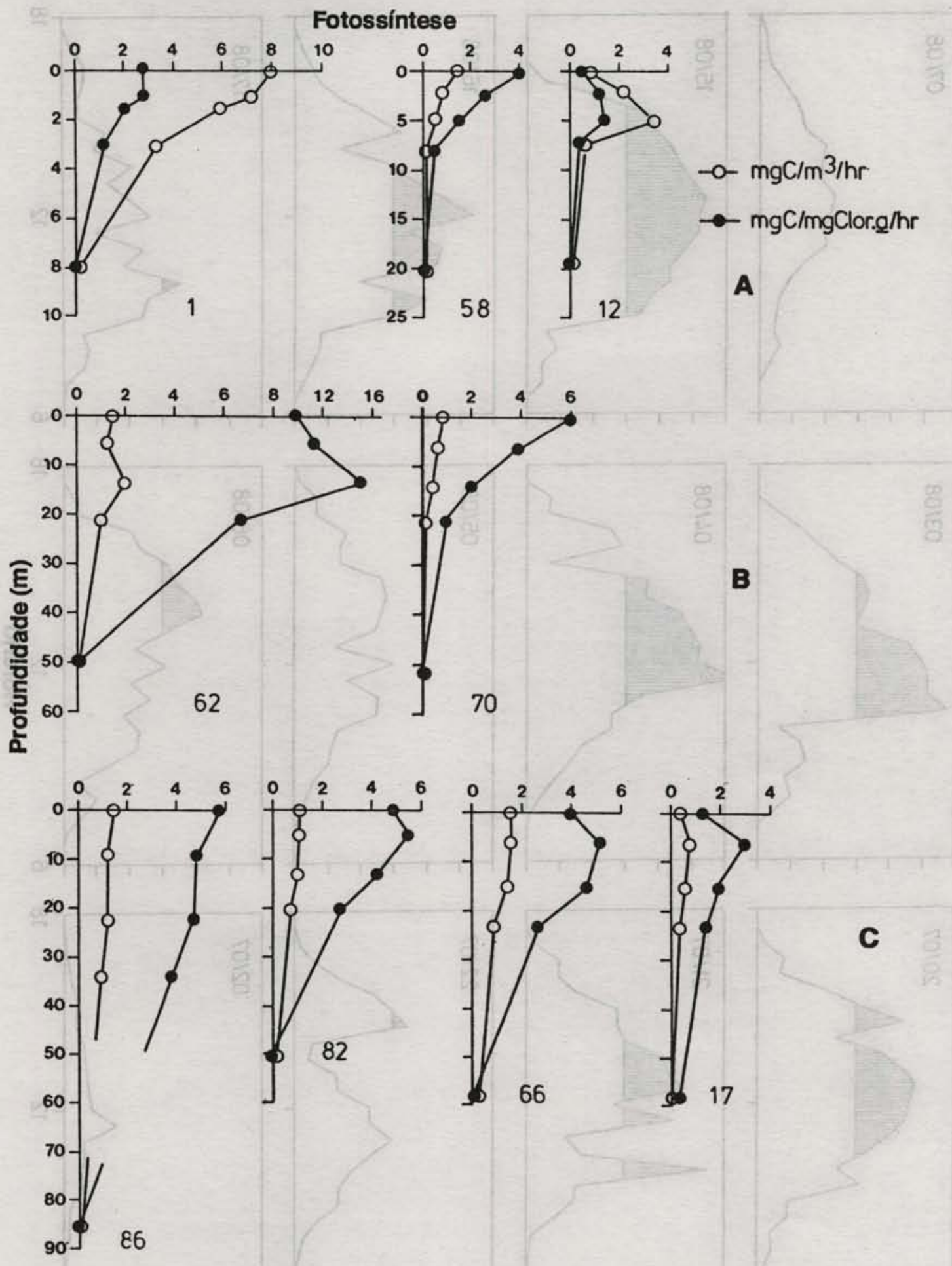

Fig. 3. Distribuição vertical da fotossíntese em estações costeiras (A), plataforma intermediária (B) e oceânicas (C) da Região Sueste, no inverno de 1982. 
plataforma e na zona oceânica as taxas foram mais baixas e a distribuição vertical foi homogênea. Quando expressa por unidade de clorofila-a (número de assimilação) a fotossíntese apresentou um padrão de distribuição vertical semelhante em todas as estaçōes, com máximos sub-superficiais variando entre 1,38 e 15,07 $\mathrm{mgC} / \mathrm{mgClor} . \mathrm{a} / \mathrm{h}$ (est. 12 e 62 , respectivamente) decrescendo em direção à base da zona eufótica. Em maio de 1983, a fotossíntese por unidade de volume de água e por unidade de clorofila- $a$ (Fig. 4 ) variaram respectivamente de 0,01 a $3,79 \mathrm{mgC} / \mathrm{m}^{3} / \mathrm{h}$ e de 0,04 a $6,11 \mathrm{mgC} / \mathrm{mgClor} . a / \mathrm{h}$. Nas estaçōes 63 e 79 (intermediárias) e na estação oceânica 67 , os máximos foram obtidos na superfície. Na estação costeira 41 o maximo foi observado a $2,5 \mathrm{~m}$. O padrão de distribuição vertical foi praticamente o mesmo observado no inverno, ou seja, valores máximos na superfície decrescendo regularmente até um mínimo na base da zona eufótica.
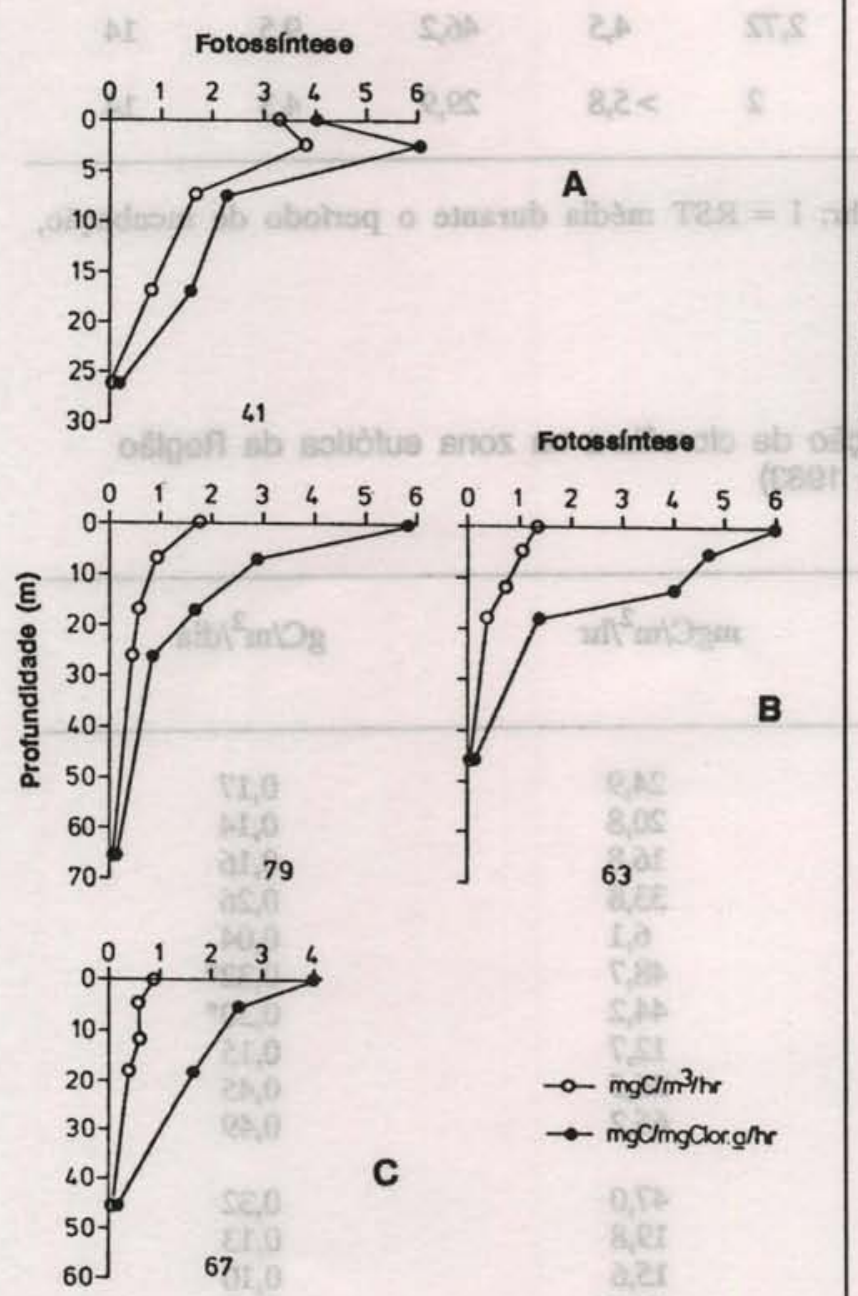

C

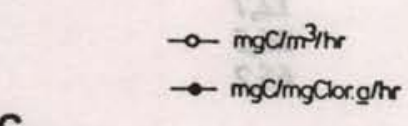

Fig. 4. Distribuição vertical da fotossíntese em estações costeiras (A), plataforma intermediária (B) e oceânicas (C) da Região Sueste, no outono de 1983.

\section{Taxas de fotossintese em amostras fracionadas}

A Tabela 2 apresenta as taxas de fotossíntese em amostras fracionadas no outono de 1983 . O nanofitoplâncton $(<20 \mu \mathrm{m})$ fotoassimilou mais de $70 \%$ do carbono inorgânico nas estaçōes 64 e $60,96 \%$ na estação 72 e $100 \%$ na estação 83.

Tabela 2. Taxas de fotossintese total e fracionadas, em amostras de superfície na Região Sueste (maio de 1983)

\begin{tabular}{|c|c|c|c|c|}
\hline Est. & Dia & Total & $\begin{array}{l}\mathrm{mgC} / \mathrm{m}^{3} / \\
\mathrm{hr}\end{array}$ & $\%$ total \\
\hline 64 & 26 & 0,83 & 0,59 & 71 \\
\hline 68 & 27 & 0,40 & 0,30 & 75 \\
\hline 72 & 28 & 1,60 & 1,53 & 96 \\
\hline 83 & 29 & 0,59 & 0,59 & 100 \\
\hline
\end{tabular}

Relaçōes fotossintese $x$ luz

Na Figura 5 estão representadas as relações fotossíntese $x$ luz na superfície das estaçōes 17, 38, 62 e 66 durante o inverno de 1982. A taxa máxima de fotossíntese obtida sob intensidades saturantes de luz, Fmax, variou de 1,50 a $9,53 \mathrm{mgC} / \mathrm{mgClor} . \mathrm{a} / \mathrm{hr}$ (est. $17 \mathrm{e}$ 62 , respectivamente). $\mathrm{O}$ índice de fotoadaptação - Ik (Talling, 1957) variou de 7 a 14 watts.cm ${ }^{2}$ nas estaçōes 17 e 62 , respectivamente. Em nenhum experimento houve inibição da fotossíntese em altas intensidades de radiação.

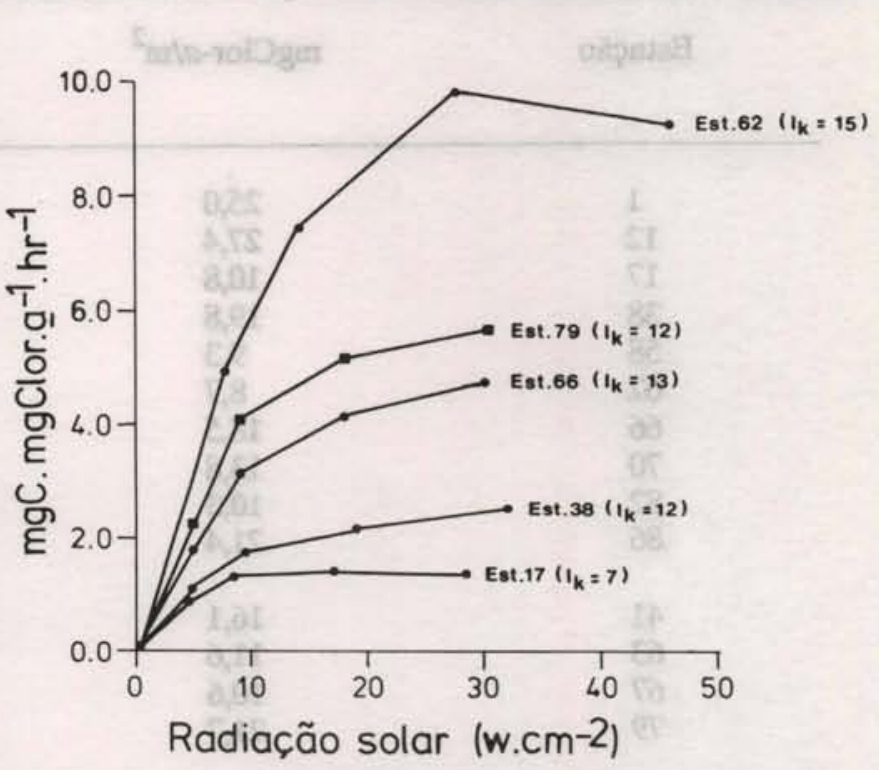

Fig. 5. Relações fotossintese $x$ luz em amostras de superfície no inverno de $1982(\bullet)$ e outono de $1983(\bowtie)$. Região Sueste do Brasil. 
Os parâmetros fotossintéticos e os dados físico-químicos de cada estação estão sumarizados na Tabela 3. As estaçōes 62 (plataforma intermediária) e 66 (oceânica) apresentaram maiores Fmáx e Ik. Nessas mesmas estaçōes, as concentrações de nutrientes foram mais elevadas, principalmente na estação 62 . Os dados de temperatura e salinidade indicam que todas as estaçōes estavam localizadas em áreas oligotroficas dominadas pela Corrente do Brasil.

\section{Produçào primária}

As taxas de produção primaria na zona eufotica estão indicadas na Tabela 4. No inverno de 1982, a produção variou de $6,1 \mathrm{a} 65,1 \mathrm{mgC} / \mathrm{m}^{2} / \mathrm{hr}$ ( $=0,04 \mathrm{a} 0,49 \mathrm{gC} / \mathrm{m}^{2} /$ dia $)$ com o valor mínimo na estação 58 localizada em frente à Baía de Paranaguá e o máximo obtido na estação oceânica 86 , localizada sobre o talude continental.

Tabela 3. Parametros físico-químicos e fotossintéticos na superfície de áreas de plataforma e oceânicas. Regiăo Sueste, inverno de 1982

\begin{tabular}{lrrrrrrrrr}
\hline Est. & $\mathrm{T}{ }^{\circ} \mathrm{C}$ & $\mathrm{S} \%$ o & $\mathrm{SiO}_{2}$ & $\mathrm{PO}_{4}$ & $\mathrm{NO}_{3}$ & $\mathrm{~N} / \mathrm{P}$ & $\mathrm{I}$ & Fmáx & IK \\
\hline 17 & 21,0 & 36,2 & 2,0 & 0,03 & 1,61 & - & 28,6 & 1,5 & 7 \\
38 & 21,5 & 36,5 & 2,7 & 0,22 & 1,21 & 5,5 & 32,0 & 2,5 & 12 \\
62 & 19,5 & 35,2 & 12,4 & 0,60 & 2,72 & 4,5 & 46,2 & 9,5 & 14 \\
66 & 21,8 & 36,5 & 5 & 0,34 & 2 & $>5,8$ & 29,9 & 4,3 & 14 \\
\hline
\end{tabular}

Obs.: nutrientes em $\mu \mathrm{mol} /$; Fmáx em mgC/mgClor-a/hr; I = RST média durante o período de incubação, em watts.cm ${ }^{2}$

Tabela 4. Taxas de produção primária e concentração de clorofila-a na zona eufótica da Região Sueste (julho/agosto de 1982 e maio de 1983)

Estaçảo $\mathrm{mgClor}-a / \mathrm{m}^{2} \quad \mathrm{mgC} / \mathrm{m}^{2} / \mathrm{hr} \quad \mathrm{gC} / \mathrm{m}^{2} / \mathrm{dia}$

$\cdot(*)=0,20$ pelo método da clorofila 
No outono de 1983, o valor mínimo de 15,66 $\mathrm{mgC} / \mathrm{m}^{2} / \mathrm{hr}\left(=0,10 \mathrm{gC} / \mathrm{m}^{2} /\right.$ dia $)$ foi obtido na estação oceânica 67 , e o valor máximo de $47,0 \mathrm{mgC} / \mathrm{m}^{2} / \mathrm{hr}(=0,32$ $\mathrm{gC} / \mathrm{m}^{2} / \mathrm{dia}$ ) foi observado na estação 41 , no litoral norte de Santa Catarina. Valores intermediários de 19,8 e 27,2 $\mathrm{mgC} / \mathrm{m}^{2} / \mathrm{hr}\left(=0,13\right.$ e $0,19 \mathrm{gC} / \mathrm{m}^{2} /$ dia $)$ foram obtidos respectivamente nas estaçōes intermediárias 63 e 79 , sobre a plataforma intermediária de São Paulo.

A variação diária da radiação solar total e da taxa de fotossíntese, em todos os níveis de luz amostrados nas estaçōes 62 e 66 (Fig. 6), foram obtidas a partir das equaçōes (1) e (2). O cálculo da produção primária na zona eufótica, pelo método da clorofila, resultou valores obtidos praticamente os mesmos em ambas as estaçōes, equivalentes a $0,20 \mathrm{gC} / \mathrm{m}^{2} /$ dia.

Estação 62
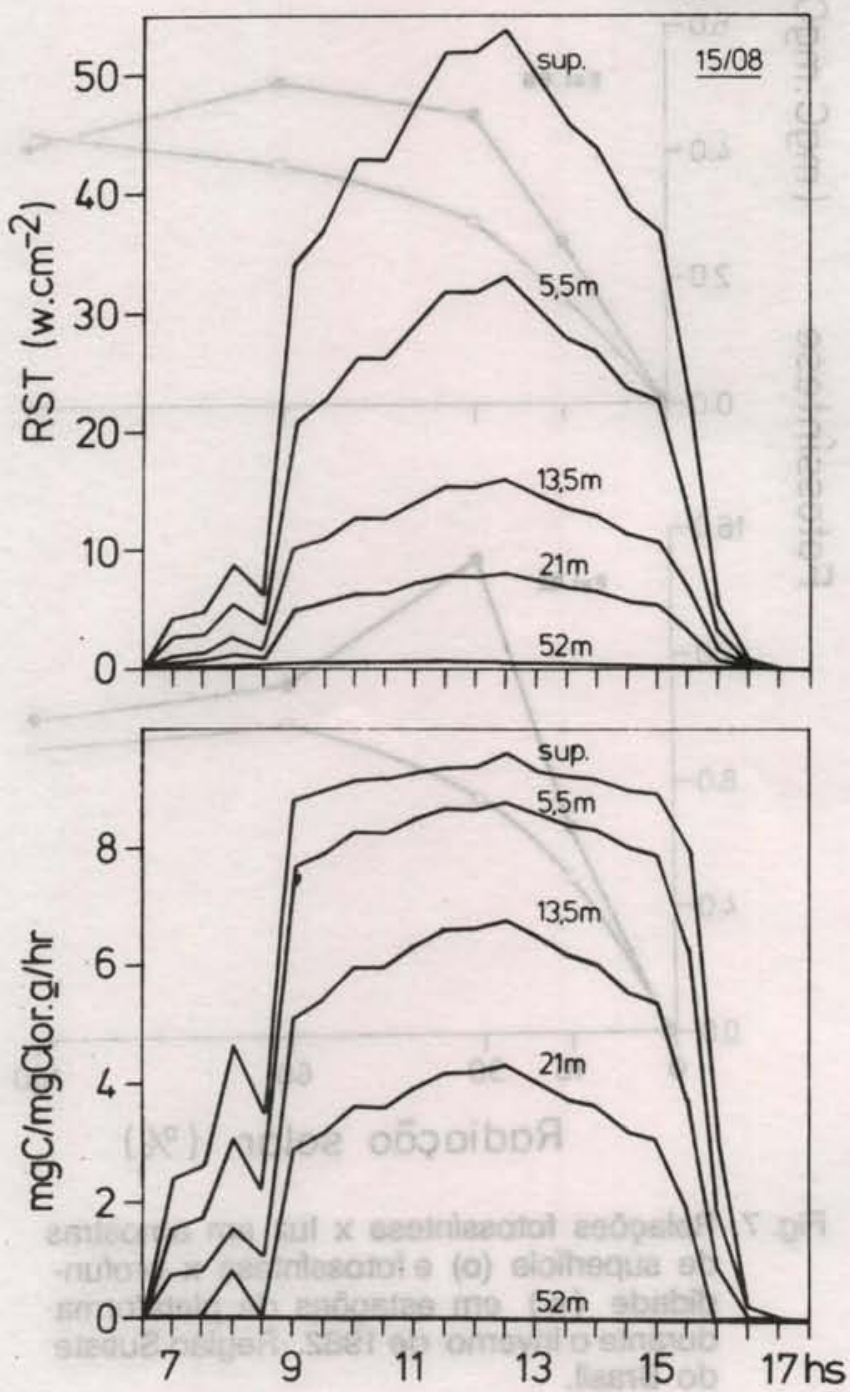

\section{Discussão}

A maior parte das informações sobre as taxas de produçāo primária do fitoplâncton marinho foram obtidas com a técnica do C-14. Apesar das dificuldades para se aplicar a técnica nas condiçōes ideais sugeridas por Colijn et al. (1983), a técnica do C-14 continua sendo amplamente utilizada na maioria dos estudos de produtividade, principalmente quando realizados em áreas afastadas da costa.

No presente trabalho, dois métodos diferentes de estimativas de produção orgânica na zona eufótica foram empregados simultaneamente em duas estaçōes oceanográficas: a estação 62 , localizada em águas de plataforma, com menor salinidade e temperatura e maior concentraçāo de silica e fósforo; e a estaçāo 66 , localizada
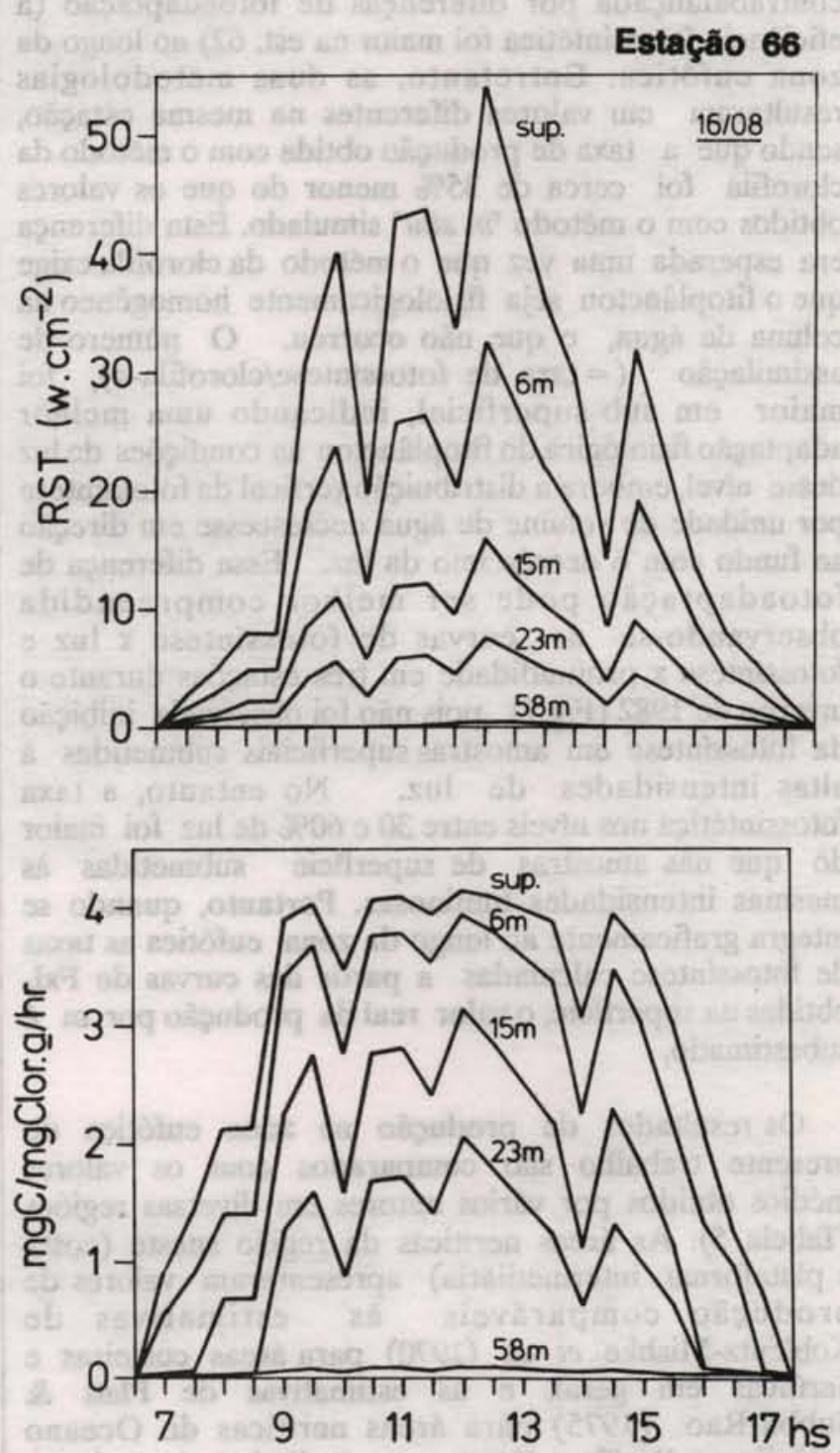

Fig. 6. Variação diária da radiação solar total (RST) e da taxa de fotossíntese (calculada a partir da equação 2) nas profundidades correspondentes aos níveis de $100,60,30,16$ e $1 \%$ de luz incidente na superfície, no inverno de 1982. Região Sueste do Brasil. Est. 62 e Est. 66. 
em área oceânica com baixa concentraçāo desses nutrientes. A concentração de nitrogênio inorgânico (principalmente nitrato) foi limitante em ambas as estaçōes, com razões N:P em torno de 4,5 e 5,8 nas estaçōes 62 e 66 , respectivamente. De acordo com Brandini (1986) as concentraçōes de amônia obtidas na superfície dessas estaçōes foram significativamente baixas quando comparadas com o nitrato $(0,04$ e 0,28 $\mu \mathrm{mol} / 1$ nas estações 62 e 66 , respectivamente) e, portanto, não foram consideradas no cálculo da razão N:P. Apesar de localizadas em massas de água diferentes, com diferentes concentraçōes de nutrientes e clorofila- $a$, as taxas de produçāo foram praticamente iguais quando obtidas com o método da clorofila e muito semelhantes quando obtidas com o método "in situ" simulado. Provavelmente, a diferença na concentraçāo de clorofila (menor na est. 62 e maior na est. 66) foi contrabalançada por diferenças de fotoadaptaçã̉o (a eficiência fotossintética foi maior na est. 62) ao longo da zona eufótica. Entretanto, as duas metodologias resultaram em valores diferentes na mesma estaçāo, sendo que a taxa de produçāo obtida com o método da clorofila foi cerca de $35 \%$ menor do que os valores obtidos com o método "in situ" simulado. Esta diferença era esperada uma vez que o método da clorofila exige que o fitoplâncton seja fisiologicamente homogêneo na coluna de água, o que não ocorreu. O número de assimilação (=taxa de fotossíntese/clorofila- $a$ ), foi maior em sub-superficial, indicando uma melhor adaptaçāo fisiológica do fitoplâncton às condiçōes de luz desse nível, embora a distribuição vertical da fotossíntese por unidade de volume de água decrescesse em direção ao fundo com o decréscimo da luz. Essa diferença de fotoadaptaçảo pode ser melhor compreendida observando-se as curvas de fotossíntese $\mathrm{x}$ luz e fotossíntese $\mathrm{x}$ profundidade em três estaçōes durante 0 inverno de 1982 (Fig.7), pois não foi observada inibição da fotossíntese em amostras superficiais submetidas à altas intensidades de luz. No entanto, a taxa fotossintética nos níveis entre 30 e $60 \%$ de luz foi maior do que nas amostras de superfície submetidas às mesmas intensidades luminosas. Portanto, quando se integra graficamente ao longo da zona eufótica as taxas de fotossíntese calculadas a partir das curvas de FxL obtidas na superfície, o valor real da produção por m é subestimado.

Os resultados de produção na zona eufótica do presente trabalho são comparados com os valores médios obtidos por vários autores em diversas regiōes (Tabela 5). As áreas neríticas da regiāo sueste (costa e plataforma intermediária) apresentaram valores de produçāo comparáveis às estimativas de Koblentz-Mishke et al. (1970) para áreas costeiras e neríticas em geral, e às estimativas de Platt \& Subba-Rao (1975) para áreas neríticas do Oceano Atlântico e Pacífico. Entretanto, os limites de variação obtidos no presente trabalho foram inferiores aos valores apresentados por Sorokin (1963) e Estrada (1974) para as áreas de ressurgência no noroeste da Africa. As áreas oceânicas da região sueste, apesar de dominadas pela massa de Água Tropical oligotrófica da Corrente do Brasil, apresentaram valores de produçāo superiores aos dos giros subtropicais (Koblentz-Mishke et al., 1970).
Teixeira \& Tundisi (1967) obtiveram valores 10x inferiores em águas do Atlântico Equatorial.

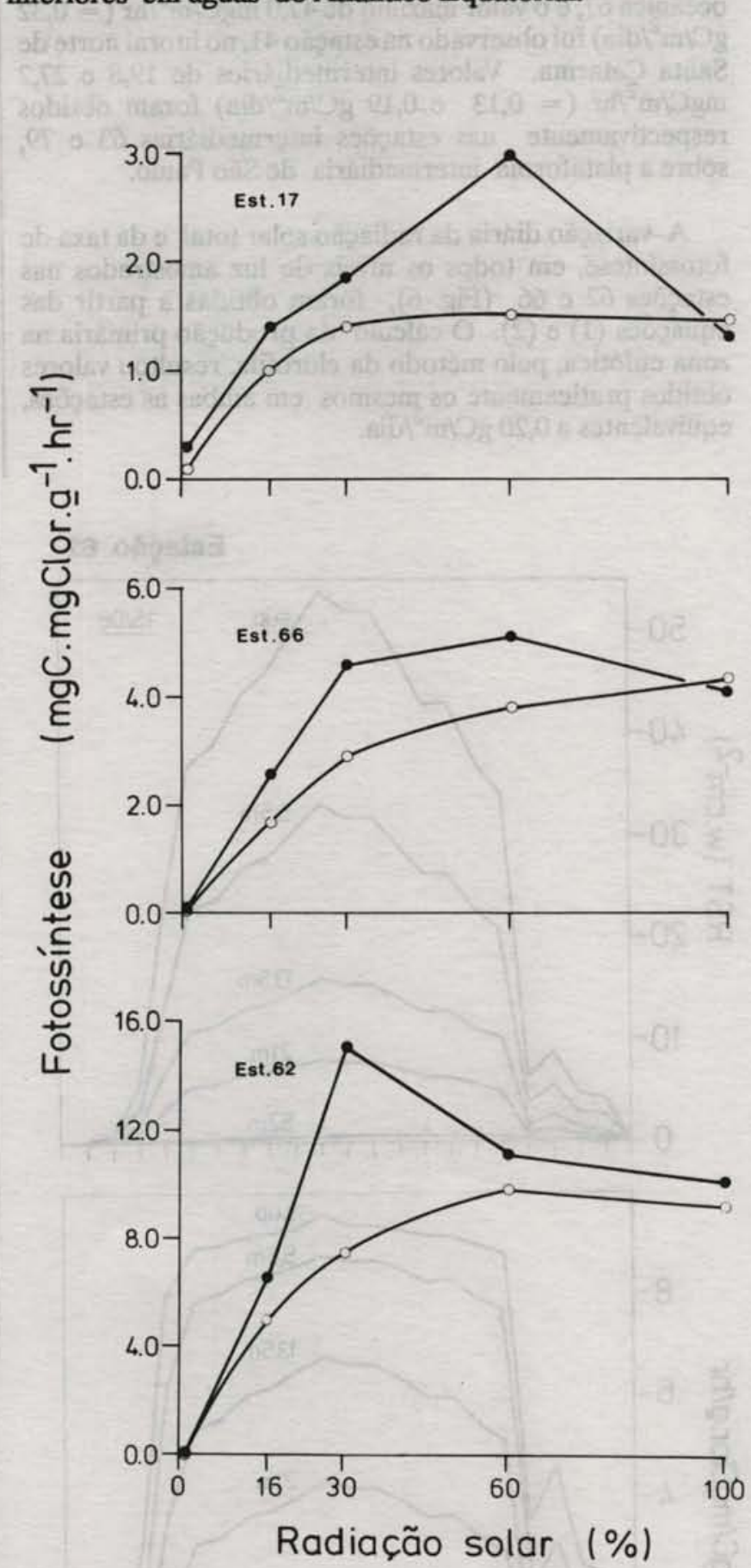

Fig. 7. Relações fotossíntese $x$ luz em amostras de superfície (o) e fotossíntese $x$ profundidade $(\bullet)$ em estações de plataforma durante o inverno de 1982. Região Sueste do Brasil.

Brandini (1988a, 1990) analisou a estrutura oceanográfica da área estudada e comentou a sua semelhança com as regiōes sueste dos Estados Unidos e Austrália. Nos mesmos períodos estudados no presente trabalho, foram detectadas zonas de mistura entre 
massas de água subantárticas e tropicais na altura da costa catarinense, principalmente no inverno, representando os limites extremos da Convergência Subtropical associados à ressurgências da Água Central do Atlântico Sul (Matsuura, 1986). A mistura de massas de água provoca uma variação geográfica acentuada de fatores ambientais (temperatura, nutrientes) que afetam a distribuição da biomassa e composiçāo do fitoplâncton. Isto explica parcialmente a grande variabilidade nas taxas de produção obtidas na regiāo sueste. As estações $1,12,30$ e 58 estão localizadas em áreas costeiras e intermediárias, comparativamente mais ricas em nutrientes do que a Água Tropical.

Entretanto, também ocorreram diferenças marcantes na produçāo, em estaçōes localizadas na mesma massa de água, provavelmente associadas à diferenças na estrutura taxonômica da comunidade fitoplanctônica. A análise de amostras de fitoplâncton total e os estudos de distribuição geográfica dos principais grupos taxonômicos (Brandini, 1988b) revelaram que, com excessāo dos fitoflagelados que dominaram em todas as estaçōes, as áreas costeiras e intermediárias da costa de Santa Catarina foram dominadas por diatomáceas, dinoflagelados e silicoflagelados. Cocolitoforídeos e cianofíceas dominaram no restante das estaçōes.

Além dos aspectos metodológicos discutidos e da heterogeneidade ambiental que ocorre na coluna eufótica da região sueste, a produção primária pode ter sido subestimada devido à excreçâo fitoplanctônica. De acordo com Vieira \& Teixeira (1981) em amostras oceânicas da região sueste, até $30 \%$ do carbono fotoassimilado pode ser excretado durante o período de incubação, com valores relativos crescentes em direção às águas oceânicas.

Em publicaçōes recentes (Brandin et al, 1989; Brandini, 1990) foi discutida a importância dos máximos subsuperficiais de clorofila nos estudos de produçāo e como eles afetam a produçāo anual em regiōes de plataforma. Holligan et al.(1984) mencionaram que, em áreas oceânicas, esses picos ocorrem na altura de $1 \%$ de luz não contribuindo significativamente para a produção anual, ao passo que, em áreas de plataforma, eles são mais desenvolvidos no verâo em profundidades entre 5-10\% de luz, perfazendo uma fraçāo significativa da produção anual. No presente trabalho, a coleta de água foi feita em níveis discretos utilizando-se garrafas de Van Dorn. Certamente, esta não é a metodologia mais adequada nos estudos de produção na coluna de água uma vez que os "picos verdadeiros" de clorofila são dificilmente detectados.

Além dos fatores ambientais e metodológicos responsáveis pela variação nas medidas de produção, ainda restam os fatores biológicos como herbivoria, excreção, adaptação fisiológica à luz, microdistribuiçāo, etc., que afetam a taxa de produção, mesmo em uma massa de água homogênea do ponto de vista físico-químico. De qualquer modo, apesar das dúvidas quanto aos valores absolutos, as variaçōes ou as homogeneidades espaciais podem ser detectadas se a metodologia for padronizada, dando umé idéia básica

Tabela 5. Taxas diárias de produção na zona eufótica da Região Sueste do Brasil e em outı วs oceanos

Região $\mathrm{gC} / \mathrm{m}^{2} / \mathrm{dia} \quad$ Referência

\begin{tabular}{lccc}
\hline & Nerítica & Oceânica & \\
\hline $\begin{array}{l}\text { Oceanos } \\
\text { Índico }\end{array}$ & 0,71 & 0,23 & Platt \& Subba Rao (1975) \\
Atlântico & 0,41 & 0,28 & Platt \& Subba Rao (1975) \\
Pacífico & 0,52 & 0,15 & Platt \& Subba Rao (1975)
\end{tabular}

\section{Áreas}

costeiras

neríticas

equatoriais

giros subtropicais

NW África

$$
\begin{gathered}
0,25-0,50 \\
0,50 \\
0,10-0,50 \\
0,10 \\
>0,1 \\
0,2-1,0
\end{gathered}
$$

0,01-0,05
Koblentz-Mishke et al. (1970)

Koblentz-Mishke et al. (1970)

Koblentz-Mishke et al. (1970)

Koblentz-Mishke et al. (1970)

Sorokin (1963)

Estrada (1974)

Teixeira \& Tundisi (1967)

Presente trabalho

Presente trabalho

Presente trabalho
$0,04-0,32$

0,13-0,45

$0,10-0,49$ 
sobre as relaçōes entre produçāo e parâmetros ambientais.

\section{Resumo}

Taxas de produção primária do fitoplâncton (C-14) foram obtidas em 14 estaçōes da plataforma intermediária e áreas oceânicas da regiấo sueste do Brasil, no inverno de 1982 e outono de 1983. O cálculo da produção na zona eufótica foi feito utilizando-se o método in situ simulado. Em duas ocasiôes, a taxa de produção foi estimada com base nos dados de clorofila- $a$ e radiaçāo solar diária, e os resultados obtidos foram comparados com os obtidos pelo método in situ simulado.

A taxa de produção variou de $0,04-0,49 \mathrm{gC} / \mathrm{m}^{2} / \mathrm{d}$. Os resultados obtidos com o método da clorofila foram cerca de $35 \%$ menores.

Alem dos experimentos de produção, foram estudadas as características fotossintéticas do fitoplâncton através da relação fotossíntese $\mathrm{x}$ luz. $\mathrm{O}$ número de assimilaçāo cresceu com a profundidade indicando uma fotoadaptação das populaçōes fitoplanctônicas dos estratos intermediários da zona eufótica (30-60\% de luz), em relaçāo às populaçōes de superfície.

\section{Agradecimentos}

Agradeço aos colegas João R. M. Silva e Carola A. C. Thamm pelo auxilio nos trabalhos de coleta, e a Ricardo Queiroz pelas análises das amostras de C-14 no Instituto Oceanográfico da USP. Aos oficiais e demais tripulantes do N/Oc."Almirante Saldanha" pelo apoio durante toda a OPERAÇĀO SUESTE I e II. Agradeço, ainda, à Diretoria de Hidrografia e Navegação - MM, por ceder os dados hidrográficos e todo o material necessário para as análises de clorofila e experimentos de fotossíntese.

\section{Referências bibliográficas}

AIDAR-ARAGĀO, E.; TEIXEIRA, C. \& VIEIRA, A. A.H. 1980. Produçāo primária e concentração de clorofila- $a$ na costa brasileira (Lat. $22^{\circ} 31^{\prime}$ 'S - Long. $41^{\circ} 52^{\prime} \mathrm{W}$ a Lat. $28^{\circ} 43^{\prime} \mathrm{S}$ - Long. $\left.47^{\circ} 57^{\prime} \mathrm{W}\right)$. Bolm Inst. oceanogr., S Paulo, 29(2):9-14.

BRANDINI, F. P. 1986. Hidrografia e características do fitoplâncton na regiāo sueste do Brasil: produçāo primária, biomassa e composição. Tese de doutorado. Universidade de São Paulo, Instituto Oceanográfico. 110p.

1988a. Hydrography, phytoplankton biomass and photosynthesis in shelf and oceanic waters off Southeastern Brazil during autumn (May/June 1983). Bolm Inst. oceanogr., S Paulo, 36(1/2): 63-72.
BRANDINI, F. P. 1988b. Composição e distribuição do fitoplâncton na Regiāo Sueste e suas relaçōes com as massas d'agua (Operação Sueste I inverno/1982). Ciênc. Cult., S Paulo, 40(4):334-341.

1990. Hydrography and characteristics of the phytoplankton in shelf and oceanic waters off Southeastern Brazil during winter (July/August 1982) and summer (February/March 1984). Hydrobiologia, 196:111-148.

\& MORAES, C. L. B. 1986. Composiçāo e distribuiçāo do fitoplâncton em áreas costeiras e oceânicas da Região Sueste do Brasil. Nerítica, Pontal do Sul,1(3):9-19.

\& THAMM, C. A. C. 1989. Shelf break upwelling, subsurface maxima of chlorophyll and nitrite, and vertical distribution of a subtropical nano-microplankton community off Southeastern Brazil. In: BRANDINI, F. P., ed. Memórias do III Encontro Brasileiro de Plâncton, Curitiba. 190p.

DIRETORIA DE HIDROGRAFIA E NAVEGAÇĀO - Ministério da Marinha. 1985. Relatório da 99a Comissāo Oceanográfica Sueste II. 20p.

DIRETORIA DE HIDROGRAFIA E NAVEGAÇÃO - Ministério da Marinha. 1986a. Relatório da 98a Comissão Oceanográfica Sueste I. 24p.

DIRETORIA DE HIDROGRAFIA E NAVEGAÇĀO Ministério da Marinha. 1986b. Relatório da $100^{\mathrm{a}}$ Comissão Oceanográfica Sueste III. 23 p.

COLIJN, F; GIESKES, W. W. C. \& ZEVENBOOM, W. 1983. The measurement of primary production: problems and recommendations. Hydrobiol. Bull., $17(1): 29-51$.

CUSHING, D. H. 1975. Marine ecology and fisheries. Cambridge, Cambridge University Press. 278p.

DUGDALE, R. C. \& GOERING, J. J. 1967. Uptake of new and regenerated forms of nitrogen in primary productivity. Limnol. Oceanogr., 12:196-206.

EMILSSON, I. 1961. The shelf and coastal waters off Southern Brazil. Bolm Inst. oceanogr., S Paulo, 11(2):101-112.

ESTRADA, M. 1974. Photosynthetic pigments and productivity in the upwelling region of NW Africa. Tethys, $6(1 / 2): 247-260$.

HOLLIGAN, P. M.; BALCH, W. M. \& YENTSCH, C. M. 1984. The significance of subsurface chlorophyll, nitrite and ammonium maxima in relation to nitrogen for phytoplankton growth in stratified waters of the Gulf of Maine. J. mar. Res., 42:1051-1073. 
JABLONSKI, S. \& MATSUURA, Y. 1985. Estimate of exploitation rates and population size of skipjack tuna off the southeastern coast of Brazil. Bolm Inst. oceanogr., S Paulo, 33(1): 29-38.

JITTS, H. R. 1963. The simulated in situ measurement of oceanic primary production. Austr. J. mar. Freshwat. Res., 14(2):139-147.

KOBLENTZ-MISHKE, O. J.; VOLKOVINSKY, V. V. \& KABANOVA, J. G. 1970 . Plankton primary production of the world ocean. In: Scientific Exploration of the South Pacific. Washington, D.C., National Academy of Sciences. p.183-193.

LASKER, R. 1978. The relation between oceanographic conditions and larval anchovy food in the California Current: identification of factors contributing to recruitment failure. Rapp. P.-v. Réun. Cons. int. Explor. Mer, 173:212-230.

MATSUURA, Y. 1986a. Estimativa de taxa de explotaçāo, recrutamento e biomassa do estoque da sardinha-verdadeira, Sardinella brasiliensis, na regiāo sudeste do Brasil. Ciênc. Cult., S Paulo, 38(5):892-904.

1986b. Contribuição ao estudo da estrutura oceanográfica da região sudeste entre Cabo Frio (RJ) e Cabo de Santa Marta Grande (SC). Ciênc. Cult., S Paulo, 38(8):1439-1450.

MESQUITA, A. R.; LEITE, J. B. A. \& RIZZO, R. 1983. Note on the shelf break upwelling off the Southeast coast of Brazil (Lat. $\left.26^{\circ} 30^{\prime} \mathrm{S}\right)$. Bolm Inst. oceanogr., S Paulo, 32(2):193-198.

MIRANDA, L. B. 1982. Análise de massas de água da plataforma continental e da região oceânica adjacente: Cabo de São Tomé (RJ) a Ilha de São Sebastiāo (SP). Tese de livre-docência. Instituto Oceanográfico, Universidade de São Paulo. 123 + apêndice 30p.

PAIVA, M. P. 1986. O mar e os interesses nacionais do Brasil. Bolm Ciên. Mar, (42):1-22.

PARSONS, T. \& TAKAHASHI, M. 1973. Biological oceanographic processes. Oxford, Pergamon Press. 186p.

PLATT, T. \& SUBBA RAO, D. V. 1975. Primary production of marine microphytes. In: Cooper, J. P., ed. Photosynthesis and productivity in different environments. London, Cambridge University Press. p.249-280.

POOLE, H. H. \& ATKINS, W. R. G. 1929. Photoelectric measurements of submarine illumination throughout the year. J. mar. biol. Ass. UK, 16:297-324.

RYTHER, J. H. 1969. Photosynthesis and fish production in the sea. Science, 166:72-76.
\& YENTSCH, C. S. 1957. The estimation of phytoplankton production in the ocean from chlorophyll and light data. Limnol. Oceanogr., 2:281-286.

SCOR-UNESCO W. G. 17. 1966. Determination of photosynthetic pigments. Monogr. oceanogr. Methodol., U.N., 1:9-18.

SOROKIN, Y. I. 1963. Primary organic production in the Atlantic Ócean. Hydrobiologia, 22:306-316.

SMITH, P. E. \& EPPLEY, R. W. 1982. Primary production and the anchovy population in the Southern California Bight: comparison of time series. Limnol. Oceanogr., 27(1):1-17.

STEEMANN-NIELSEN, E. 1952. The use of radioactive carbon (C-14) for measuring organic production in the sea. J. Cons. int. perm. Explor. Mer, 18:117-140.

STRICKLAND, J. D. H. 1958. Solar radiation penetrating the ocean. A review of requirements, data and methods of measurement, with particular reference to photosynthetic productivity. J. Fish. Res. Bd Can., 15(3):453-493.

\& PARSONS, T. R. 1972. A practical handbook of seawater analysis. Bull. Fish. Res. Bd Can., (167):1- 311.

SVERDRUP, H. U.; JOHNSON, M. W. \& FLEMING, R. H. 1942. The oceans: their physics, chemistry and, general biology. Englewood Cliffs, Prentice-Hall. 1087p.

TALLING, J. F. 1957. Photosynthetic characteristics of some freshwater plankton diatoms in relation to underwater radiation. New Phytol., 56:29-50.

TEIXEIRA, C. \& TUNDISI, J. G. 1967. Primary production and phytoplankton in equatorial waters. Bull. mar. Sci., 17(4):884-891.

VIEIRA, A. H. \& TEIXEIRA, C. 1981. Excreção de matéria orgânica dissolvida por populaçōes fitoplanctônicas da costa leste e sudeste do Brasil. Bolm Inst. oceanogr., S Paulo, 30(1):9-25.

VOLLENWEIDER, R. A., ed. 1969. A manual on methods for measuring primary production in aquatic environments. Oxford, Blackwell. 213p. 